\title{
Formação Docente como ambiente de pensamento: projeto representacional e processos narrativos
}

Teacher Education as an environment of thinking: the representative project and narrative processes La formación del profesorado como entorno de pensamiento: diseño representacional y procesos narrativos

DANiela B. S. FReIRE ANDRAde (iDa ÂNGELA CRISTINA LISBOA COSTA (D) b

\section{Resumo}

O presente trabalho propõe uma análise psicossocial do processo formativo de profissionais da Educação Infantil orientada pela teoria das representações sociais. São privilegiadas as articulações entre representações sociais e processos narrativos, partindo-se do princípio que a narrativa atua tanto como construção sociocognitiva da realidade, quanto como qualidade paradigmática do espaço. A narrativa contribui para a constituição de um ambiente de pensamento no interior do qual são compartilhados novos conteúdos representacionais que delineiam determinado projeto representacional. Noções como obrigação do tipo contratual, confiança interpessoal e confiança epistêmica são analisadas como fatores que contribuem para o reconhecimento da legitimidade dos processos autorais dos participantes envolvidos e a Universidade Federal do Mato Grosso (UFMT), Cuiabá, MT, Brasil. Doutora em Educação, e-mail: freire.d@terra.com.br

b Universidade Federal do Mato Grosso (UFMT), Cuiabá, MT, Brasil. Mestre em Educação, e-mail: profang@gmail.com 
da sua configuração enquanto fórum permanente de aprendizagem e desenvolvimento profissional e pessoal. Apresenta-se análises sobre o caso do projeto de formação Cribiás, Crianças Sabidas e seu pressuposto: Educação Infantil como Espaço Narrativo. Foram realizadas observações e entrevistas com um grupo de 32 profissionais cuja análise de dados gerou núcleos de significações e eixos interpretativos. Os resultados revelam que o processo formativo potencializou 0 tensionamento do campo representacional e o compartilhamento de novos significados sobre a prática docente na Educação Infantil. O projeto representacional inscrito nas narrativas compartilhadas atuou na iminência de saberes construídos coletivamente.

Palavras-chave: Representações Sociais. Narrativa. Formação de Professores.

\section{Abstract}

The present work proposes a psychosocial analysis of the educational process of Early Childhood Education professionals guided by the theory of social representations. The articulations between social representations and narrative processes are privileged, assuming that the narrative acts both as a socio-cognitive construction of reality and as a paradigmatic quality of space. The narrative contributes to the constitution of an environment of thinking within which new representational contents are shared and it describes a certain representational project. Notions such as contractual obligations, interpersonal trust and epistemic trust are analyzed as factors that contribute to the recognition of the legitimacy of the authorial processes of the participants involved and of their configuration as a permanent forum for learning and professional and personal development. It sets the analyzes about the case of the Cribiás, crianças sabidas about its assumption: Early Childhood Education as a narrative space. Observations and interviews were conducted with a group of 32 professionals whose data analysis generated nuclei of meanings and interpretive axes. The results reveal that the formative process potentiated the tension of the representational field and the sharing of new meanings about the teaching practice in Early Childhood Education. The representational project inscribed in the shared narratives acted on the imminence of collectively constructed knowledge.

Keywords: Social Representations. Narrative. Teacher Education.

\section{Resumen}

El presente trabajo propone un análisis psicosocial del proceso educativo de los profesionales de la Educación Infantil guiados por la teoría de las representaciones sociales. Se privilegian las articulaciones entre representaciones sociales y procesos narrativos, partiendo del principio de que la narrativa actúa tanto como construcción socio-cognitiva de la realidad como cualidad paradigmática del espacio. La narrativa contribuye a la constitución de un entorno de pensamiento en el que se comparten nuevos contenidos representacionales que perfilan un determinado proyecto representacional. Se analizan nociones como obligaciones contractuales, confianza interpersonal y confianza epistémica como factores que contribuyen al reconocimiento de la legitimidad de los procesos 
autorales de los participantes involucrados y su configuración como foro permanente de aprendizaje y desarrollo profesional y personal. Se presentan análisis sobre el caso del proyecto Cribiás, Niños Conocidos y su supuesto: La Educación Infantil como Espacio Narrativo. Se realizaron observaciones y entrevistas con un grupo de 32 profesionales cuyo análisis de datos generó núcleos de significados y ejes interpretativos. Los resultados revelan que el proceso formativo potenció la tensión del campo representacional y el intercambio de nuevos significados sobre la práctica docente en Educación Infantil. El proyecto de representación inscrito en las narrativas compartidas actuó sobre la inminencia del conocimiento construido colectivamente.

Palavras clave: Representaciones sociales. Narrativa. Formación de profesores.

\section{Introdução}

O presente trabalho propõe uma análise psicossocial do processo formativo de profissionais da Educação Infantil orientada pela teoria das representações sociais. São privilegiadas as articulações entre representações sociais e processos narrativos partindo-se do princípio de que a narrativa pode ser reconhecida tanto como construção sociocognitiva da realidade (JOVCHELOVITCH, 2002), quanto como qualidade do espaço (SENNETT, 1990). Deste modo, afirma-se que a narrativa contribui para a constituição de um ambiente de pensamento (MOSCOVICI, 2010) no interior do qual são compartilhados novos conteúdos representacionais que delineiam determinado projeto representacional.

O principal mote do projeto representacional (BAUER; GASKELL, 2009) inscrito no processo formativo Cribiás, Crianças Sabidas (2016-atual) é: Educação Infantil como espaço narrativo (ANDRADE, 2007). Ao explorar tal mote é possível identificar que o projeto representacional articula uma rede de significações sustentada pelas noções de Pedagogias de Participação (OLIVEIRA-FORMOSINHO; FORMOSINHO, 2019) e pelas reflexões sobre a relação estabelecida entre Infância e Patrimônio (VASCONCELLOS, 2009).

A expressão Educação Infantil como espaço narrativo sugere a participação nas práticas educativas, considerando as narrativas autorais de adultos e crianças e a importância do pertencimento comunitário e cultural nos processos de aprendizagem e desenvolvimento de crianças e profissionais da Educação. 
Neste contexto, o projeto Cribiás, Crianças Sabidas caracteriza-se por ser um processo de formação de professores orientado pelos pressupostos da teoria das representações sociais (MOSCOVICI, 2010; JODELET, 2001, JOCVHELOVITCH, 2008; BAUER; GASKELL, 2009) com ênfase na perspectiva dialógica de Marková (2017b) e nos estudos sobre processos narrativos de Jovchelovitch (2002).

A expressão metafórica Cribiás, é anunciada como objetivação do pressuposto Educação Infantil como Espaço Narrativo, uma vez que revela, por meio da imagem de crianças sabiás, uma representação de criança associada a ideia de protagonismo, conferindo concretude à prática pedagógica proposta.

Neste artigo, o potencial formativo do projeto Cribiás, Crianças Sabidas será analisado por meio de um estudo de caso (MARKOVÁ, 2017b) que envolveu um grupo de 32 profissionais da Educação Infantil da Rede Municipal de Cuiabá, participantes da edição de 2018. A produção de dados foi orientada pela observação participante no contexto dos encontros formativos (LÜDKE; ANDRÉ, 1986) e entrevistas individuais semiestruturadas (GASKELL, 2008; AGUIAR; OZELLA, 2013). A análise de dados inspirou-se nos estudos sobre núcleos de significação (AGUIAR; OZELLA, 2013) e nas estratégias de triangulação de dados (APOSTOLIDIS, 2006)

Desta maneira, a indagação deste trabalho pode ser assim formulada: em que medida o processo formativo Cribiás, crianças sabidas demostrou ser um contexto de negociação e compartilhamento de significados propicio para a emergência de mudanças no campo representacional com impactos nos processos identitários de professores?

\section{Notas sobre Representações Sociais e Processos Narrativos no contexto da formação docente}

\subsection{Da Tríade Representacional à noção de Projeto Representacional}

Em seu artigo intitulado: A fabricação da teoria das representações sociais, Marková (2017a) integra três imagens esquemáticas e, por meio destas, coloca em diálogo a noção de tríade representacional proposta por Moscovici (2010), a expansão temporal 
do triângulo representacional concebida por Bauer e Gaskell (1999) e o modelo proposto por Tânia Zittoun (2014 apud MARKOVÁ, 2017a) em seus estudos sobre aprendizagem como um processo social.

Marková (2017a) enfatiza que a teoria das representações sociais se organiza em torno da arquitetura da representação definida a partir da relação sujeito — outro, a mesma se dá por meio da comunicação cuja dinâmica gera objetos de conbecimento em uma interação triangular.

A interação é retratada no triângulo representacional moscoviciano Sujeito1-Sujeito2-Objeto —, e demostra os modos como as pessoas produzem, criam sentidos e compreendem os fenômenos sociais que constituem a realidade social.

Como destaca Moscovici (2010), é no universo consensual que a sociedade é tida como um conjunto de pessoas capazes de falar em nome do grupo, com o objetivo de tornar o não familiar em algo familiar.

Segundo este entendimento, o pensamento pode ser considerado um ambiente (MOSCOVICI, 2010), uma atmosfera social e cultural que forja convenções preliminares, atuando na interpretação da realidade e orientando condutas.

No âmbito das representações sociais, essa dinâmica é possível graças a ação de seus processos formadores: 1- ancoragem, que busca enraizar uma ideia estranha a um sistema de categorias conhecidas, presentes na memória, permitindo compará-las, interpretá-las, classificá-las e nomeá-las; 2- objetivação, transforma a imagem nomeada em algo concreto.

Para que tal processo se efetive, Marková (2017 a, b) ressalta a dialogicidade como epistemologia da vida cotidiana e das práticas profissionais. A autora defende a interdependência do Ego (S1) e Outros (S2), na qual Outros (S2) podem ser entendidos como outros sujeitos, ou suas produções como instituições, tradições situadas cultural e historicamente e costumes morais.

A autora enfatiza que o triângulo representacional moscoviciano é um dos princípios da epistemologia dialógica, pelo seu caráter dinâmico e pela polifasia cognitiva, anunciando a coexistência de diferentes tipos de conhecimento e imaginação.

Alerta ainda que a construção do conhecimento não é um processo neutro, “[...] Está repleto de tensões na compreensão e nas emoções, na confiança e 
desconfiança, em assumir e evitar responsabilidades" (MARKOVÁ, 2017b, p. 162) conforme as conjunturas sociais, históricas e pessoais.

Neste entendimento, sublinha-se a noção de projeto representacional (BAUER; GASKELL, 1999), e a incorpora à tríade (S1-S2-O) destacando a dimensão temporal para identificar a historicidade de uma representação social, revelando que a mesma apresenta pontos de contato com o passado e, ao mesmo tempo, permite a projeção do futuro revelando a imagem de um projeto $(\mathrm{P})$.

Por sua vez, o modelo de Zittoun (2014, apud Marková, 2017a) considera a esfera subjetiva para ressaltar o diálogo interior que resulta do conhecimento e experiências anteriores registradas na memória de cada sujeito dentro da tríade representacional. A autora propõe acrescentar no triângulo S1-S2-O um prisma, anunciando o sentido de elemento cultural para a pessoa. Este pressuposto considera que o objeto do conhecimento é obtido por duas linhas: uma representada pelo sentido do elemento cultural para a pessoa; e a outra linha representada pelo pensamento social e culturalmente reconhecido.

Tais observações chamam a atenção para o fato de que o sujeito, ao mesmo tempo que se insere nas comunicações inter e intra grupais sobre o objeto de conhecimento, estabelece constante diálogo consigo sobre o mesmo. Este diálogo se dá na confluência entre o conhecimento organizado, experimentado, advindo da sua cultura pessoal (aquilo que já se sabe sobre o objeto de conhecimento) e o objeto de conhecimento em si, ancorado nos sistemas formais de aprendizagem, cujo conhecimento é considerado válido social e culturalmente pelo contexto.

Ao pensar a formação de professores como processo de aprendizagem social e desenvolvimento humano que se dá no âmbito da dialogicidade, tem-se que Cribiás, Crianças Sabidas delineia um ambiente de pensamento orientado por um projeto representacional que se desenha no presente $(\mathrm{P})$ a partir de pressupostos teóricos e metodológicos na perspectiva de uma pedagogia da participação (OLIVEIRAFORMOSINHO; FORMOSINHO, 2019), que une S1 (cada participante) - S2 (o coletivo do grupo) ao $O$ (objeto de representação: o pressuposto Educação Infantil como Espaço Narrativo).

O referido processo formativo permite ao grupo de pessoas (profissionais da educação, coordenadoras pedagógicas, diretoras, assessoras, estudantes de graduação 
e pós graduação) em um determinado contexto, compartilhar e negociar significados por meio de estratégias simbólicas em diálogo com representações historicamente construídas sobre pressupostos teórico-metodológicos da Educação Infantil, a fim de tornar familiar, o não familiar.

A formação Cribiás, Crianças Sabidas pode ser caracterizada como princípio que promove uma prática pedagógica aberta às autorias de crianças e adultos, como um projeto inscrito no presente e que, no âmbito da possibilidade, confere contornos para o futuro.

No estudo de Lorensini (2018), com a mesma população, o não familiar presente na apropriação da expressão Educação Infantil como Espaço Narrativo remete aos princípios da educação emancipadora e das pedagogias participativas contemplados pelo pressuposto. Nesta direção, a imprevisibilidade do trabalho docente, aberto à criação da prática pedagógica e ao diálogo com a infância pela via da narrativa, pode ser considerada uma novidade. Por sua vez, o estranho, anunciado pela novidade, questiona o lugar das profissionais da Educação costumeiramente dedicado à reprodução de conteúdos, as metodologias transmissivas, atuantes no centro da cena educacional e no controle dos processos comunicacionais. O contraponto é promovido por uma prática pedagógica inspirada nos atos criativos e dialógicos. Tais práticas, a favor da centralidade da cultura e das autorias de crianças e adultos no contexto do diálogo intergeracional, favorecem a emergência de um projeto cultural para a infância.

\subsection{Narrativa: construção sociocognitiva da realidade e qualidade do espaço}

No escopo deste trabalho é possível pensar a narrativa tanto como modalidade discursiva que opera na construção sociocognitiva da realidade, quanto como elemento paradigmático que confere qualidade ao espaço ${ }^{1}$.

\footnotetext{
${ }^{1}$ Importante ampliar este debate considerando a distinção entre espaço e lugar. Para Jodelet (2002) o espaço (dimensão física) pode ser subjetivado e ganha o status de lugar portando assim uma identidade. Lugar, é um elemento sócio físico que é organizado, ocupado e transformado pelo ser humano por meio de um filtro de ideias, crenças, valores e sentimentos partilhados no interior de um grupo de pertença. A identidade do lugar participa na construção de processos simbólicos no interior de grupos de partilha.
} 
Sobre a primeira possibilidade, Jovchelovitch (2002) descreve a narrativa como veículo que elicia campos de experiências intersubjetivas, promovendo a compreensão das formas simbólicas, no sentido de perpetuação e de transformação da interpretação dominante sobre a vida social. Narrativas, assim como as representações sociais, são construídas a partir do léxico de um grupo social, revelando sua perspectiva de mundo. Por isso, as mesmas podem ser reconhecidas na sua relação com as representações sociais.

Narrativas são consideradas como instrumento de organização da experiência social, que tanto opera no sentido de formar representações sociais, quanto são formadas a partir destas. Nesta direção, Purkhardt (2002) afirma que a narrativa auxilia os sujeitos a tornarem o mundo um lugar estável de se viver. Este caráter construtivo da narrativa se revela em função da busca de sentidos para as experiências de vida, transformando-os em discurso.

Ainda acrescenta o autor que as narrativas são importantes não apenas como um método de pesquisa, mas, também, como um aspecto significante no processo da ciência em si, sendo consideradas modelos intelectuais regidos pelos processos de integração e seleção.

As reflexões de Andrade (2019) permitem analisar o contexto da formação profissional, levando em consideração que cientistas usam narrativas. Assim como nos processos formativos orientados pelo princípio da dialogicidade, participantes e formadores contam histórias sobre seus interesses, suas vivências, suas ideias e suas pesquisas. As modalidades discursivas para tal feito podem ser reconhecidas por meio de programas de ensino, de pesquisa, encontros informais, leituras recomendadas, conferências, textos técnicos de relatório de pesquisa ou artigos de jornais e livros. De modo geral, é possível concordar com a premissa que anunciam cientistas, assim como professores e formadores como contadores de histórias. Ao mesmo tempo, torna-se oportuna a observação de Mazzotti (1995) que aproxima a metáfora da noção de modelo, utilizado pela ciência, sendo esta última responsável pela organização do discurso.

Narrativa, tomada como um modelo intelectual, aspecto significante no processo da ciência e, metáfora, tomada como modelo científico, associam-se com o que Pléh (2002) sugere ao propor o entendimento da narrativa como uma metateoria, 
uma metáfora, considerada um instrumento de integração dos eventos organizados na mente humana.

A partir deste entendimento, a mediação da narrativa pode ser considerada uma estratégia fértil de interpretação e organização sociocognitiva da realidade interna e externa, tornando a realidade estável a partir de organização de esquemas e scripts socialmente partilhados. Eis aqui o fundamento da narrativa Cribiás, uma metáfora, um emblema que objetiva um sistema de pensamento ou nas palavras de Moscovici (2010) um ambiente de pensamento, uma atmosfera social e cultural que forja convenções preliminares atuando na interpretação da realidade. Tais narrativas científicas, de história de vida ou mesmo societais, quando compartilhadas em contextos formativos, podem contribuir para que estes se constituam como espaços potencialmente narrativos.

A noção espaço narrativo é aqui assumida como um elemento paradigmático que confere qualidade ao espaço educacional ou formativo.

A expressão Educação infantil como Espaço Narrativo foi forjada por Andrade (2007) em seu artigo A criança na Educação Infantil: por entre Emílias e Chapeuz̧inhos. Esta expressão foi baseada na noção espaço narrativo proposta pelo sociólogo Sennett (1990). O conceito de espaço narrativo é apresentado em contraposição ao espaço linear, referindo-se a disjunção entre o espaço público e privado, e entre a vida interiorizada, insider, e a vida nas ruas, outsider.

Sennett (1990, p. 190) propõe o conceito de espaço narrativo como uma forma de tempo no espaço: “O espaço pode se tornar pleno de tempo quando ele permite que certas propriedades de narrativas operem na vida cotidiana”. O que move a proposta de Sennett (1990) é a consciência da necessidade de se resgatar o interior e o exterior a partir do desmoronamento do muro, da fronteira, fazendo emergir a noção de unidade orgânica, na sua complexidade. Esse seria, segundo Sennett (1990), o desafio dos urbanistas: reviver a realidade do exterior como uma dimensão da experiência humana.

Andrade (2007) considera que espaço narrativo está próximo de uma abstração, uma vez que são espaços que narram uma ficção para fazer com que o lugar tenha um sentido, um caráter, constituindo, nessa medida, a personificação das vivências de seus usuários no espaço. 
Em consonância com as discussões de Gonçalves, Santos, Aragusuku e Andrade (2016) o espaço narrativo como é caracterizado como espaço aberto à manifestação da novidade, eventos imprevisíveis que orientam a produção criativa presente em diferentes modos de ser e estar no mundo. Nestes espaços de reconhecimento das diferenças circulam histórias, também nomeadas como narrativas encorajadoras (ANDRADE, 2017), estas podem ser anunciadas como texto real - narrativa apresentada pela cultura - e como texto virtual(BRUNER, 2002), isto é, como objeto de interpretação e ponto de partida para outras histórias - versões dos interlocutores.

\subsection{A formação docente como ambiente de pensamento orientado pela obrigação do tipo contratual e pela confiança epistêmica}

No âmbito da aprendizagem social observa-se íntima relação entre processos identitários e a adesão às representações sociais. Sobre tal aspecto é preciso considerar que para Lloyd e Duveen (1992) as representações sociais são evocadas nas interações sociais quando os sujeitos envolvidos compreendem a situação e se reconhecem, assim como a seus interlocutores, como sujeitos sociais.

As análises de Duveen e Lloyd (1986, apud ANDÉRSEN, 2010) anunciam a relação existente entre processo identitário e as representações sociais consensuais compartilhadas no grupo de pertencimento. Sobre tal aspecto, os teóricos destacam que atores sociais assumem posições em relação ao sistema coletivo de significados definidas pelas representações sociais internalizadas. A internalização das representações sociais possibilita o delineamento de uma identidade social (identidade profissional, neste caso) aspecto que remete a ideia de ator social independente.

No entanto, os autores asseveram que a influência que as representações sociais exercem nos indivíduos podem assumir formas distintas, uma vez que as individualidades não são apreendidas independentemente das relações sociais e, por esta razão, as mesmas representações sociais sustentam diferentes identidades sociais.

Neste raciocínio, os autores anunciam dois tipos de influência das representações sociais, a depender das relações sociais vivenciadas no interior dos 
grupos de pertença: 1. Influência do tipo obrigação imperativa e 2. Influência do tipo obrigação contratual.

A influência das representações sociais em contextos orientados pela obrigação imperativa se dá quando um indivíduo se vê obrigado a adotar uma identidade social, em particular motivado por exigência externa. Tais exigências derivam dos modos como os demais identificam os atores sociais em termos de categorias sociais. Já na influência das representações sociais do tipo contratual, o ator social se integra em um grupo e estabelece um contrato que o motiva a adotar uma determinada identidade social.

Lloyd e Duveen (1992) ainda consideram que quando existe mutualidade no entendimento construído por diferentes participantes é possível reduzir a necessidade de qualquer especificação explícita ou negociação de identidades sociais. Em condições onde não existe mutualidade ou ainda quando a mesma foi rompida, a negociação de identidades sociais pode envolver a coordenação de diferentes pontos de vista e a resolução de conflitos.

De outro modo, Marková (2017b) anuncia a mutualidade no entendimento construído por diferentes participantes por meio das noções de confiança interpessoal e da confiança epistêmica.

Em um contexto formativo, nota-se pelos estudos de Zittoun (2014 apud MARKOVÁ, 2017a) que a confiança epistêmica está relacionada à confiança interpessoal na qual, ao iniciar uma ação formativa, os participantes com menos experiências necessitam confiar que o formador está comprometido com a temática a ser estudada e que se importa com eles. Igualmente, o formador precisa perceber em cada participante a disposição para aprender em uma relação onde se estabelece a confiança epistêmica no primeiro. Para isso, o formador necessita demonstrar confiança nas capacidades dos participantes, de forma que estes a percebam, possibilitando a existência de relações interpessoais, falando-lhes de suas paixões e interesses, expressando claramente a crença na sua inovação e criatividade, convidando dessa forma, cada participante à reciprocidade, concedendo-lhes autonomia, garantindo sua posição de quem tem algo a ensinar à um grupo de pessoas que desejam aprender. 
Assim motivados, os atores sociais se mostram dispostos a aprenderem uns com os outros. Portanto, na relação dialógica a confiança epistêmica do $S 1$ (cada participante) no $S 2$ (o coletivo que constitui o grupo) substitui a incapacidade de descobrir e compreender sozinho os fenômenos sociais e naturais.

No âmbito deste estudo indaga-se sobre as dimensões presentes no processo formativo e de que forma as informações, cognições, comunicações, relações e afetividade foram anunciadas no interior do Cribiás, Crianças Sabidas.

\section{Procedimentos metodológicos}

A presente pesquisa caracterizou-se como um estudo de caso único, sendo possível analisar a interdependência Ego-Outro no contexto do processo formativo Cribiás, Crianças Sabidas-2018. Neste entendimento, discute-se a possibilidade de generalização teórica contribuindo com implicações para outros estudos que tomem como base a triangularidade do Ego-Alter-Objeto (MARKOVÁ, 2017 a, b).

A produção de dados foi orientada pela observação participante (LÜDKE; ANDRÉ, 1986) e entrevistas semiestruturadas (GASKELL, 2008) com o objetivo de compreender os significados compartilhados no interior das trocas sociais vivenciadas ao longo do projeto formativo.

A amostra $(n=32)$ foi assim distribuída: 12 coordenadoras pedagógicas; 02 diretoras; 03 professoras, 10 técnicas de desenvolvimento infantil; 05 assessoras pedagógicas.

As observações foram realizadas ao longo dos encontros mensais de 2018 $(\mathrm{n}=8)$, cujos conteúdos foram devidamente registrados no caderno de campo. Os dados gerados estabeleceram relação direta com a programação do processo formativo e as entrevistas semi-estruturadas foram realizadas após seu término.

O banco de dados gerados pelas observações foi analisado compreensivamente levando-se em consideração o compartilhamento de significados e os tensionamentos anunciados nos debates.

Já os dados gerados pelas entrevistas foram sistematizados segundo a noção de núcleos de significação (AGUIAR; OZELLA, 2013). Após, em um exercício de triangulação de dados (APOSTOLIDIS, 2006), foram nomeados eixos interpretativos gerados a partir dos dados da observação e da entrevista. 


\section{Apresentação e discussão de dados}

A triangulação dos dados permitiu a identificação de dois eixos interpretativos e cinco núcleos de significação assim organizados:

Eixo 1 - Tensionamentos do campo representacional:

- O grupo infantil como elemento orientador do planejamento pedagógico;

- O eu e o outro na relação pedagógica.

Eixo 2 - Cribiás como ambiente de pensamento: a familiarização do estranho:

- A imprevisibilidade da prática pedagógica na perspectiva dialógica;

- Cribiás: uma metáfora para liberdade e autonomia na cena educacional;

- Formação docente: reflexão, dialogicidade e processos identitários.

\section{Eixo 1 - Tensionamentos do campo representacional}

O eixo 1 denominado Tensionamentos do campo representacional refere-se as narrativas compartilhadas na primeira parte do processo formativo, dedicada a problematização do campo e as primeiras iniciativas orientadas pelo estranhamento do familiar - Educação centrada no profissional da educação. Para tanto, considerou-se as narrativas das professoras sobre suas impressões relativas às dinâmicas do comportamento das crianças de modo a anunciar estas últimas como principal elemento orientador do planejamento pedagógico.

O objetivo se referia ao desenvolvimento de análises orientadas pela perspectiva psicossocial para o grupo sendo possível identificar a criança na relação com seus pares e o grupo de crianças na relação com a professora, configurando um sistema a partir do qual as decisões sobre o planejamento pedagógico e seu desenrolar seriam tomadas.

- O grupo infantil como elemento orientador do planejamento pedagógico 
A análise dos dados relacionada a esse núcleo de significação destacou três tensionamentos principais do campo representacional:

1. A representação da criança indisciplinada e problemática, que deve obedecer x a representação da criança em processo de aprendizagem e desenvolvimento, que ainda necessita aprender a viver em grupo por meio da mediação dos demais atores sociais, em especial do adulto;

2. Grupo infantil como a soma de todas as crianças x grupo infantil como uma unidade que se autorregula;

3. A representação de planejamento pedagógico - orientado a partir do prescritivo $\mathrm{x}$ orientado a partir do narrativo.

As narrativas das profissionais sobre a observação do comportamento infantil apresentaram duas abordagens distintas. $\mathrm{Na}$ primeira destacou-se a disputa e comportamentos não colaborativos por parte de algumas crianças. Nesta abordagem o mote central dos argumentos trazia a hipótese da criança "indisciplinada e problemática”, para a qual a ação pedagógica deveria ser desenvolvida com objetivos adaptacionistas. Em contraposição, o mesmo comportamento foi anunciado na segunda abordagem a partir da hipótese da criança em processo de aprendizagem e desenvolvimento infantil. Nesta perspectiva o comportamento social estaria relacionado à iminência de comportamentos colaborativos, potencializados pela mediação da professora.

Com relação ao tensionamento sobre grupo infantil, observou-se que a dimensão grupal promovida pela dinâmica dos comportamentos das crianças e seus pares, e entre elas e a professora, foi silenciada, relevando a tendência das professoras em delinear a dimensão social como a soma das crianças, subtraindo os efeitos dos compartilhamentos e tensionamentos no interior do grupo infantil, e entre este e a professora, em um processo de autorregulação. De outro modo, observou-se o esforço das profissionais ora em problematizar uma criança em especial, ora em delinear análises individualizadas, excluindo aquilo que de fato seria o ponto central da sua ação pedagógica - o grupo.

Dos treze relatos sobre a observação das crianças, três apresentaram como foco conteúdos representacionais ancorados na ideia de criança-problema, privilegiando 
a dimensão individual, com destaque para os comportamentos infantis classificados como possivelmente patológicos, aparecendo nas falas casos específicos de crianças autistas, crianças "mordedoras" e crianças consideradas egocêntricas e agressivas.

Observei durante as brincadeiras com blocos e carrinhos que tem um aluno que tudo ele quer ser o primeiro, primeiro da fila, todos os brinquedos só para ele. Diante desta atitude as crianças deixam de brincar com ele. Se irrita quando não é o primeiro, bate, emburra. Com a outra professora ele manipulava, tirava o foco das atividades propostas, então sinto que ele precisa se integrar (Professora Canário da Terra, EMEB C, $1^{\circ}$ ano Cribiás, 19 anos na educação, sendo 04 na educação infantil, 25/09/2018, Diário de Campo).

Quanto aos outros dez relatos apresentaram conteúdos representacionais ancorados na ideia de criança protagonista, como se observa na análise das falas a seguir:

Após a ida na horta as crianças fazem registro a partir das questões sobre o que temos na horta. [...] ao questionar as professoras sobre como tinha sido a ida na horta, disseram: "Ah encontraram um passarinho morto no meio do caminho", e ao voltarem para sala após colheita dos tomatinhos, as crianças disseram "Tia tinha um passarinho morto!" e os desenhos das crianças foram mais do passarinho morto do que dos alimentos da horta. Ao perguntar sobre o que fizeram com o passarinho morto, as TDIs disseram: "jogamos no lixo". Agora todas as vezes que as crianças vão para a horta elas ficam procurando o passarinho morto, nós não falamos para as crianças que jogamos fora, e não sabemos o que fazer diante do questionamento das crianças sobre o passarinho morto. Naquele momento para as educadoras era apenas um passarinho morto. A questão é: como a gente conversa com as crianças sobre a morte? (Coordenadora Uirapuru, Creche $C, 3^{\circ}$ ano Cribiás, 20 anos na educação, sendo 18 anos na educação infantil, 26/09/18, Diário de Campo)

Com relação a essa parcela dos profissionais, observa-se nas suas narrativas o destaque para a dinâmica do grupo, ancorando-se na ideia de criança como ator social. As ênfases sublinharam a produção de narrativas infantis, valorização das brincadeiras, movimento e desenhos, com uma demanda para o planejamento do projeto pedagógico voltado ao processo de imaginação e criação.

Pelos primeiros relatos identificou-se ancoragem nos aspecto normativos do processo de socialização, na perspectiva da reprodução do comportamento desejável. Em seu contraponto, pode-se notar alguns relatos focalizados nos processos lúdicos e autorais das crianças-perspectiva da criação.

Em ambas focalizações o grupo infantil, como unidade de atenção e intervenção pedagógica, ainda se mostrava invisibilizado.

No tensionamento nomeado como prática pedagógica prescritiva x prática pedagógica narrativa considerou-se que esta última mobilizou narrativas que se referiam à organização da rotina, fato que envolvia os demais profissionais da unidade 
educacional tendo em vista que a gestão do tempo passaria a ser orientada pelas ações e prioridades pedagógicas, não mais pelo cumprimento de horários fixados previamente. Tal debate suscitou reflexões sobretudo com relação à representação da rotina como sequência fixa e inegociável de procedimentos, relacionada a higiene e alimentação, anunciadas como práticas divorciadas no planejamento pedagógico. Neste exercício, a prática pedagógica narrativa provocou certo tensionamento frente à prática pedagógica prescritiva, que traz o pressuposto do adulto como o único responsável por definir o que e como trabalhar com as crianças.

Neste tensionamento a perspectiva narrativa envolve: a análise sobre os processos de aprendizagem e desenvolvimento de cada criança e de como estas atuam no grupo e, também, o impacto na gestão do tempo por consequência da rotina. Neste caso, o tempo passaria a ser regulado não apenas pelas demandas dos adultos, mas também pelas implicações relativas aos desejos e curiosidades das crianças.

Tem que ter esforço para fazer, porque chega no final você tem uma rotina para ser cumprida e o que vale é o que está ali, então exigem da gente que você faça conforme a rotina, se é bem feito ou não, não importa desde que faça. É o sistema, ele exige de você. $E$ você participando deste Projeto você vê que quando você vai para a prática, não é assim, não interessa se eu vou atrasar um pouquinho se uma criança vai precisar de mais tempo que o outro, pra mim eu já vejo assim, não interessa aquela rotina que está ali, você tem que ver a criança (Técnica em Desenvolvimento Infantil João Pinto, Creche $N, 1^{\circ}$ ano Cribiás, 15 anos na educação, sendo 04 anos na educação infantil).

Frente aos novos pressupostos da Educação na perspectiva narrativa, muitas participantes expressaram estar diante de algo novo, desconhecido, sendo difícil nomeá-lo, classificá-lo e mesmo objetivá-lo.

Liberdade das crianças e eu me liberto das minhas amarras enquanto adulto, me liberto para ver a criança realmente como ela é, porque eu saio do meu pedestal. [...] Antes do Projeto eu não via essa possibilidade da narrativa como essa potente ferramenta pedagógica, eu achava que eu, adulto, deveria conduzir o pedagógico, mesmo a gente falando da criança ser protagonista, e sujeito de direito, né (Coordenadora Bem-te-vi-azul, CMEI C, $3^{\circ}$ ano Cribiás, 19 anos na educação, sempre atuação na educação infantil).

Em suas falas as participantes demonstraram que, ao modificar o referencial para se pensar o planejamento pedagógico começando pelo observar a criança, adotouse a perspectiva de desenvolver uma prática narrativa que se faz pelo encontro das 
crianças com os adultos, pela relação eu e o outro, pelas histórias de cada um compartilhadas diariamente e que se tornam a história do grupo.

[...] Esse adulto atípico, esse profissional que vê a criança na sua singularidade, que não é o detentor do saber, que se vê protagonista junto com a criança, juntos fazem um trabalho bacana, de sucesso, porque não tem esse detentor de conhecimento, a criança traz elementos, pra que o adulto atípico aflore (Assessora Canarinho, 1 ano Cribiás (2017), 09 anos na educação, sempre na educação infantil).

Deste modo, inicia-se o processo de significações da expressão: Educação Infantil como Espaço Narrativo delineando um ambiente de pensamento no interior do qual são compartilhadas representações sociais sobre criança, seu processo de aprendizagem e desenvolvimento, sua dinâmica grupal na relação com seus pares e com a profissional de educação, um sistema de saberes que impactam o delineamento das práticas pedagógicas.

\section{O eu e o Outro na relação pedagógica}

Neste núcleo de significação, observa-se as narrativas associadas aos valores orientadores do contrato psicológico, este que confere contorno às trocas sociais entre adultos e crianças, adultos e adultos.

Alteridade é aqui anunciada como valor emancipatório, indicando crianças e profissionais da educação como atores sociais. Nos relatos observa-se o ser, estar e aprender com o outro com ênfase na escuta como um elemento da ação docente.

Sentir capaz de novas formas de ensinar, [...] dá a segurança para o professor ser protagonista da sua prática. O fortalecimento de grupo mesmo, porque daí você tem mais pessoas fazendo, você não se sente sozinha, como se tivesse uma sustentação. Existe possibilidades (Coordenadora Beija-flor-vermelho, EMEB B, $3^{\circ}$ ano Cribiás, 27 anos na educação, sendo 08 anos de atuação na educação infantil).

A partir do momento que você tem esse olhar sensivel, você vai mudar a sua prática também pra melhor, provavelmente quando se tem esse olhar sensivel não vai mais ter a questão das agressões, nós ouvimos relatos, às vezes, que acontecem de profissionais que não tem paciência, porque a agressão não é só física, não precisa nem tocar na criança, mas um olhar, um tom de voz, quer dizer essas coisas eu acho que termina sensibilizando, a postura muda (Assessora Arara-azul, 1 ano Cribiás (2017), 22 anos na educação, sendo 08 anos de atuação na educação infantil). 
A ênfase sobre a escuta sensível do outro, seja este outro a criança, a professora, a coordenadora, a assessora pedagógica ou a diretora, demonstra que o processo formativo dinamizou a singularidade e a integridade na comunicação EgoOutro sendo o outro anunciado não mais como ele e sim como você.

Em particular a análise deste núcleo revelou que a Educação Infantil como Espaço Narrativo prescinde da valorização da interdependência entre a relação professoracrianças, inserida em um contexto institucional, envolvendo outros atores que compõem a equipe pedagógica da unidade e, para além dela, uma vez que a rede pública de ensino se regula por meio de diretrizes e políticas educacionais.

\section{Eixo 2 - Cribiás como ambiente de pensamento: a familiarização do estranho}

O Eixo 2, denominado Cribiás como ambiente de pensamento: a familiarização do estranho, revela processos reflexivos das profissionais inseridas no processo formativo.

- A imprevisibilidade da prática pedagógica na perspectiva dialógica

1.

Este núcleo traz referência à imprevisibilidade da prática pedagógica e seus pressupostos, ancorados na perspectiva participativa e narrativa, em uma relação de oposição com a previsibilidade da pedagogia transmissiva e das práticas assistencialistas.

As narrativas anunciam as impressões dos profissionais sobre as práticas pedagógicas realizadas a partir dos encaminhamentos do processo formativo. Como conteúdo recorrente, sublinha-se a relação eu-outro identificada como eixo orientador de sete projetos pedagógicos, conforme demonstram os excertos a seguir:

Nunca tinha proposto isso para as crianças e fiquei encantada, realmente muda, minha sala é outra, a minha intervenção foi um aluno que não se sentia parte da sala. Ele chegou com comportamento totalmente diferente, ele não se sentia pertencente a minha turma, então durante todo o trabalho foi incrivel, ontem ao ver ele brincando no pátio, com as outras crianças, refleti olha só consegui, o trabalho surtiu efeito. Durante as etapas ele passou a se identificar com o boneco que não sabia brincar e aos poucos passou a interagir, participar das atividades [...]. Toda a turma foi mexida, no momento em que uma criança ia ficando sem abraço, dois correram e abraçaram juntos o colega, foi um trabalho bem 
bacana [...] (Professora Canário da Terra, EMEB C, $1^{\circ}$ ano Cribiás, 19 anos na educação, sendo 04 na educação infantil, 23/10/18, Diário de Campo).

Um determinado boneco que já não possuía os membros inferiores e nem superiores, dentre os brinquedos sempre era o escolhido, tratavam-no com carinho, com beijos e abraços. Todos sem exceção, o tratavam por pai, depois que a criança $L$ começou a chamá-lo assim. Diante deste fato decidimos convidar alguns pais para brincarem com a turma a partir de uma brincadeira preferida de sua infância, a fim de possibilitar inúmeras brincadeiras para se brincar no coletivo com uma pessoa do sexo masculino, resultando no projeto pedagógico Meu Amigo Grande (Coordenadora Andorinha, CMEI D, $1^{\circ}$ ano Cribiás, 10 anos na educação, sendo 09 na educação infantil, 24/10/19, Diário de Campo).

Nas falas acima observa-se que a relação: criança-grupo; criança-figuras parentais e criança-professora, atuaram como eixo das ações pedagógicas, com destaque para a complementariedade presente no brincar coletivo.

Em cinco projetos pedagógicos identificou-se a ênfase na curiosidade infantil, ao partirem do olhar da criança sobre um aspecto da realidade, conforme falas em destaque:

Na roda de conversa o Zezinho perguntou para as crianças o que elas acham que aconteceu depois que o passarinho morreu, e a criança A disse: Ele foi pro buraco; a criança B: Acho que passarinho não morre, só gato e a criança $C$ : Ele não morreu estava só fingindo (Coordenadora Uirapuru, Creche C, $3^{\circ}$ ano Cribiás, 20 anos na educação, sendo 18 anos na educação infantil24/10/18, Diário de Campo).

Tocando o chão as crianças disseram: O chão tá abrindo; Olha a caverna tia; Eu brinco ai quando a mamãe deixa. A terra tá mole, olha o buraco! (Coordenadora Andorinha, 10 anos na educação, sendo 09 anos na educação infantil, 23/10/18, Diário de Campo).

Para além da relativização da rotina, a novidade e o estranhamento anunciados como o imprevisto na ação pedagógica diz respeito à perplexidade frente às potencialidades infantis. As profissionais anunciaram a existência de grupos de crianças em pleno exercício de investigação e interpretação da realidade. Ao reconhecer a legitimidade dos saberes infantis, as profissionais encorajavam-se a relativizar a importância do controle e da previsibilidade dos processos comunicacionais na cena educacional.

[...] quando desprendemos de tudo o que está lá fora, como lançar frequência no sistema, conversar com pai, atender Conselho Tutelar e sentamos para observar as crianças a gente fica pensando: "Meu Deus do céu o que é isso?", a gente precisa mesmo de referencial teórico metodológico de que infância é essa, porque é muita coisa, uma mesma história toma caminhos diversos e quando a gente vê já foi, a gente não imagina que estaria tratando de morte a partir de comida, falando de horta pensando que poderia estar pesquisando 
ajudando essas crianças a ter um olhar pesquisador, e de repente surge um passarinho no meio do caminho (Coordenadora Uirapuru, Creche C, $3^{\circ}$ ano Cribiás, 20 anos na educação, sendo 18 anos na educação infantil, 26/09/18, Diário de Campo).

O pressuposto Educação Infantil como Espaço Narrativo foi anunciado na sua imprevisibilidade no percurso da ação pedagógica, no encontro de histórias de vidas que comunicam crenças, valores, afetos e racionalidades em processos vivenciados na horizontalidade da relação crianças-adulto.

- Cribiás: uma metáfora para liberdade e autonomia na cena educacional

2.

As narrativas das profissionais sobre o termo Cribiás revela a emergência do fenômeno anunciado por Pléh (2002), ao propor o entendimento da narrativa como uma metateoria. Deste modo, tem-se, na metáfora, um emblema que objetiva o que Moscovici (2010) anunciou como ambiente de pensamento.

A análise das significações sobre a metáfora Cribiás revelou a produção dos sentidos mais emblemáticos entorno dos pressupostos do processo formativo.

Crianças sabidas, imagem de pássaros, de liberdade, a gente sente essa liberdade com a criança, em poder ser livre, em poder interferir na ação pedagógica (Assessora Fênix, 1 ano Cribiás (2017), 08 anos na educação, sempre atuando na educação infantil).

O elemento representacional que se destaca na análise da metáfora Cribiás refere-se à representação do ato educativo como uma descoberta possível pela vivência da expressão estar com, uma ação compartilhada entre crianças e profissionais da Educação - um voo em parceria, a partir de um encontro intergeracional, no interior do qual se celebra o ato criativo e sua inerente imprevisibilidade.

As imagens evocadas revelam ainda a ideia de liberdade, de instrumentalização teórico-metodológica vivenciada na parceria do processo formativo, em uma rede de apoio do tipo contratual, instituída entre os atores sociais da secretaria de educação, da universidade e das unidades educacionais.

No âmbito das narrativas anunciadas, novas expressões passam a ser compartilhadas no campo representacional, revelando indícios de um processo de familiarização da expressão Educação Infantil como Espaço Narrativo. 
O que parece ser muito idealizado foi, no âmbito das entrevistas, nomeado estabelecendo parâmetros mais concretos para a compreensão do que as profissionais estavam se referindo ao falarem de voos, liberdade e um novo olhar para a realidade pedagógica.

Estamos engessados, a gente fica tão resistente aquilo que a criança pode transmitir para gente e nos ajudar, nosso coração endurece e parece que tudo é normal, mas não é, a gente sabe que não é, então com o Cribiás a gente vê as crianças e a gente vê o quanto é importante, cada uma tem tanto relato de histórias de vida sabe, [...] o Cribiás ajuda a aumentar a escuta, a sensibilidade (Coordenadora Águia-azul, Creche A, $3^{\circ}$ ano Cribiás, 19 anos na educação, sempre na educação infantil).

Antes era muito abstrato, conteúdos pelos conteúdo. Planejava a partir dos conteúdos e hoje é a partir da observação e da vivência com as crianças. É um outro universo, é o exercício de você enxergar a realidade e dentro da realidade você encontra o conteúdo [...] (Coordenadora Beija-flor-vermelho, EMEB B, $3^{\circ}$ ano Cribiás, 27 anos na educação, sendo 08 anos na educação na educação infantil).

A análise dos excertos destaca a dimensão formativa tanto nos seus elementos racionais, quanto atitudinais, afetivos, relacionais com forte impacto nos processos identitários. Neste caso, a formação Cribiás não se caracteriza como um acúmulo de informações, mas convida a um desvestir do adulto, o envolvendo em um processo reflexivo sobre si e sobre o outro.

$O$ adulto que tem que estar com a criança, com esse olhar atento, com esse olhar sensivel pra essa criança, eu acho que a gente tem que desvestir do adulto, daquele adulto que sabe tudo, que manda, autoritário e ficar no nível da criança até para entendê-la, porque a gente vem de uma educação tradicional em que eu mando aqui na turma, eu que sei, você tem que fazer dessa forma, se você não fizer dessa forma está errado, então quer dizer eu acho que a gente tem que dar uma repaginada em nós e no nosso olhar [...] (Assessora Beijaflor-celeste, 2 anos Cribiás (2016-2017), 19 anos na educação, sendo 09 anos na educação infantil).

O entendimento da importância do estar com o outro como um propulsor de aprendizagens, como uma possibilidade de atuar na zona de desenvolvimento eminente (VIGOTSKI, 2009), seja das crianças ou dos adultos, demonstra que o processo formativo também proporcionou em muitos momentos uma relação horizontal entre membros do grupo de pesquisa, responsáveis pela condução dos estudos (formadores) e as profissionais da educação, bem como entre assessoras/coordenadoras/professoras e professoras/crianças. 
Momento difícil, busquei ajuda na equipe, pedi orientações para as outras assessoras, todas estavam aprendendo e nessas conversas a gente fazia as trocas (Assessora Arara-azul, 1 ano Cribiás (2017), 22 anos na educação, sendo 08 anos na educação infantil).

No excerto, é possível perceber o termo Cribiás como metáfora que sugere a existência de um processo formativo para adultos e crianças marcado pela relação horizontal. Neste exercício de elaboração nota-se o uso do termo Cribiás como metáfora, instrumento de integração que anuncia certo ambiente de pensamento, uma atmosfera social e cultural, no interior do qual se forjam sentimentos de pertença e convenções preliminares, que promovem referências para interpretação e atuação na realidade.

Por essa razão e observando Zittoun (2014a, apud MARKOVÁ a, 2017), destaca-se a confiança intersubjetiva entre todos que estão envolvidos no processo formativo como um valor central, uma vez que é por sua via que os participantes desenvolvem confiança epistêmica para com quem está com a responsabilidade de ensinar.

Deste modo, ao compreender o impacto da formação Cribiás nas narrativas das participantes, pode-se dizer que pensar a Educação Infantil como Espaço Narrativo só é possível quando se estabelece um ambiente de confiança nos vínculos estabelecidos, aspecto que possibilita o desenvolvimento de processos de aprendizagem e desenvolvimento em dinâmicas que integram movimentos de reprodução e de criação.

- Formação docente: reflexão, dialogicidade e processos identitários

O processo formativo é anunciado como um espaço de participação, reflexão e aprendizagens. A formação em rede, orientada pela perspectiva da dialogicidade, gerou o sentido de não estarem sozinhas na busca por uma pedagogia participativa. Ainda, destacam-se os processos identitários das representações sociais, por revelarem o delineamento de um modo de ser e estar na docência, ancorado na perspectiva da humanização, horizontalidade nas relações e na valorização dos saberes infantis. 
[...] é a observação, mas as crianças pra mim são muito diferentes, mesmo sendo as mesmas crianças que trabalho todos os dias, mas esse projeto me trouxe uma visão assim, como se a gente não sabe nada sobre elas. Você olhando para essas crianças, trabalhando com essas crianças, o que você aprende, ouve deles, o que elas trazem pra gente, é muito significante. [...] assim como eu, todos aqui tem uma formação básica, fizemos pedagogia, mas você depara com uma coisa tão simples como você ouvir a criança, com um olhar atento para essa criança, como se eu não soubesse nada antes, estou aprendendo tudo de novo, é uma nova faculdade (Técnica em Desenvolvimento Infantil João Pinto, Creche $N, 1^{\circ}$ ano Cribiás, 15 anos na educação, sendo 04 na educação infantil, 25/09/2019, Diário de Campo).

Como já disse a angústia é minha, esse observar, esse verbo observar está martelando a cabeça, cada vez que vejo o vídeo dos registros das observações das crianças vejo alguma coisa diferente, e meu olhar enquanto professora era de um jeito e vejo que as meninas têm um jeito também. O olhar, o observar na sala na hora dos brinquedos era de uma atitude de cuidar para as crianças não machucarem e de mediar os conflitos ali. E hoje o meu olhar é diferente, é de ver as possibilidades de brincadeiras, e realmente eu não tinha esse olhar [...] (Coordenadora Águia Preta, EMEB D, $1^{\circ}$ ano Cribiás, 28 anos na educação, sendo 15 anos na educação infantil, 26/09/18, Diário de Campo).

Os relatos acima demostram que, ao compreender a narrativa como estratégia teórico-metodológica pela ação do observar a criança, repensa-se a partir do trabalho docente, a própria identidade enquanto profissional da educação, traduzindo o processo formativo como um espaço narrativo, visto que “[...] por não ter uma mensagem linear que impõe o sentido do seu uso, [...] gesta a transformação daquele que narra, porque nesse exercício, ele se revela como pessoa (ANDRADE, 2006, p. 88)".

Neste sentido, observam Lloyd e Duveen (1992), ao se perceberem como protagonista no processo formativo as profissionais evocam as representações sociais compreendendo a situação, reconhecendo o seu lugar, assim como a de seus interlocutores, e assumindo a si e aos outros como atores sociais.

Provavelmente, esta condição foi potencializada tendo em vista o que Duveen e Lloyd (1986, apud ANDRÉSEN, 2010) anunciam como obrigação do tipo contratual.

Eu tive um crescimento que eu não tive em todos esses anos, desde os quinze anos, dentro deste mundo da criança, e nunca tinha visto por esse olhos, um olhar diferenciado, [...] primeiro saber porque você bateu, mas porque, o que está acontecendo em casa, você tem que questionar a criança antes de julgar. Eu cresci muito, achei que a intervenção, o processo em si me fez crescer bastante (Professora Canário-da-terra, EMEB C, $1^{\circ}$ ano Cribiás, 19 anos na educação, sendo 04 anos na educação infantil).

[...] Teve mudanças inclusive enquanto professora, totalmente diferente, é um antes e um depois mesmo, a partir dessa escuta, enquanto assessora de ouvir também, estar lá e ouvir as crianças, essa sensibilidade muda totalmente, o olhar da gente muda, o sentido da 
aprendizagem muda, como é, como ela se dá, o que faz sentido pra criança, tudo isso muda na gente, a gente passa a enxergar de um outro ângulo, de um outro patamar, é um outro olhar mesmo (Assessora Fênix, 1 ano Cribiás (2017), 08 anos na educação, sempre na educação infantil).

As narrativas demonstram o conflito, a angústia e a reflexão de quem lida com a informação e com os afetos concomitantemente, em uma descoberta relacionada à interdependência do pensar o outro e do pensar a si mesmo. Tais evidências revelam o potencial dos processos formativos orientados para o desenvolvimento humano de adultos no exercício de reelaboração de identidades sociais.

A Educação Infantil como Espaço Narrativo é anunciada como processo mais do que como produto, processos incessantes de constituição identitária de crianças e adultos, pela via da narrativa e da reflexão.

\section{Considerações finais}

A leitura psicossocial propiciada pela teoria das representações sociais permitiu a análise da formação de profissionais da Educação, a partir do estudo de caso do projeto Cribiás, Crianças Sabidas.

As trocas sociais empreendidas no processo formativo resultaram em novos saberes e operaram para a familiarização do novo e desconhecido, anunciado pela expressão Educação Infantil como Espaço Narrativo.

O projeto representacional da narrativa, que mediou as trocas sociais no interior do processo Cribiás, potencializou o tensionamento do campo representacional e o compartilhamento de novos significados sobre a prática docente na Educação Infantil. Os dados revelam que o projeto representacional inscrito nas narrativas compartilhadas atuou na iminência de saberes construídos coletivamente.

Os eixos interpretativos e os núcleos de significação permitiram destacar os indicadores desse processo assim sistematizados:

- Processos de aprendizagem e desenvolvimento, de crianças e adultos, inseridos em contextos grupais e orientados para a produção de saberes considerando o diálogo intergeracional; 
- Processo que anuncia interdependência entre os atores sociais considerando a esfera subjetiva (o ator social), intersubjetiva (os grupos) e transubjetiva (as instituições e políticas educacionais);

- Processo inscrito na confluência entre a previsibilidade e imprevisibilidade do ato educativo, aberto para encontros de histórias de vidas que comunicam crenças, valores, afetos e racionalidades vivenciadas na horizontalidade da relação crianças-grupo-adulto;

- Processo que se constitui a partir da confiança interpessoal, aspecto que possibilita aprendizagens inspiradas na confiança epistêmica;

- Processo, no sentido pleno do termo, nomeado no fluxo da reflexividade e da narratividade que marcam vivências dedicadas à interpretação da realidade e do si no mundo.

O processo formativo Cribiás, Crianças Sabidas pode, deste modo, ser considerado um fórum de formação permanente que proporciona relação dialógica, configurando um ambiente de pensamento. Este aspecto torna possível o entendimento da Educação Infantil como Espaço Narrativo, na perspectiva da imprevisibilidade e do desafio de ser a Educação Infantil, espaço aberto às novas impressões, mobilizadas pelo senso de perplexidade sobre a vida.

\section{Referências}

AGUIAR, W. M. J.; OZELLA S. Apreensão dos sentidos: aprimorando a proposta dos núcleos de significação. R. Bras. Est. Pedag., Brasília, v. 94, n. 236, p. 299-322, jan./abr. 2013. Disponível em: http://www.scielo.br/pdf/rbeped/v94n236/15.pdf. Acesso em: 25 jul. 2019.

ANDERSÉN, A. Social representations and social identity in swedish folk high schools: an application of Duveen and Lloyd. Papers on social representations, v. 19, p. 10.1-10.14, 2010. Disponíel em: http://www.Psych.Lse.Ac.Uk/psr/. Acesso em: 09 jul. 2017.

ANDRADE, D. B. S. F. AS CRIANÇAS FACE. A continuidade e a descontinuidade da mente: notas em psicologia social. Educação em Foco, v. 4, n. 3, set./dez. 2019. Disponível em: https://periodicos.ufff.br/index.php/edufoco/article/view/29158. Acesso em: 24 ago. 2020.

ANDRADE, D. B. S. F. A criança na educação infantil: por entre Emílias e Chapeuzinhos. Revista de Educação Pública, v. 16, n. 31, p. 97-104, maio-ago. 2007. Disponível em: 
http://periodicoscientificos.ufmt.br/ojs/index.php/educacaopublica/article/view/5188.

Acesso em: 17 abr. 2020.

ANDRADE, D. B. S. F. O lugar feminino na escola: um estudo em representações sociais. Orientador: Sousa, C. P. Tese (Doutorado em Psicologia da Educação) - Pontifícia Universidade Católica de São Paulo, São Paulo, SP, 2006. Disponível em: https://tede2.pucsp.br/handle/handle/16255. Acesso em: 20 jan. 2018.

ANDRADE, D. B. S. F. . Rede de apoio à infância: interfaces com a Psicologia e a Pedagogia. Projeto de Extensão, Sistema de Extensão (SIEx). Coordenação de Extensão (CODEX). Universidade Federal do Mato Grosso, Cuiabá, 2017. Disponível em : https://sistemas.ufmt.br/ufmt.siex/Comum/Projeto/Detalhes?projetoUID=1553.

Acesso: 25 ago. 2020.

APOSTOLIDIS, T. Représentations sociales et triangulation: une application em psychologie sociale de la santé. Psicologia: Teoria e Pesquisa, v. 22, n. 2, p. 211-266, 2006.

BAUER, M. W.; GASKELL, G. Towards a paradigm for research on social representations. Trad. Eliza Moura. Journal for the Theory of social behavior, v. 29, n. 2, p. 163-186, 1999.

BRUNER, J. Realidade Mental, Mundos Possiveis. Tradução Marcos A. G. Domingues. São Paulo: Artmed, 2002.

GASKELL, G. Entrevistas individuais e grupais. In: BAURER, M. W.; GASKELL, G. (editores). Pesquisa qualitativa com texto: imagem e som: um manual prático. Trad. Pedrinho A. Guareschi. Petrópolis: Vozes, 2008.

GONÇALVES, N.M.;SANTOS, R.C.; ARAGUSUKU, H. A.; ANDRADE, D.B.S.F. Narrativa e novas formas de cuidado em Saúde Mental. In: Cadernos Brasileiros de Saúde Mental, vol.8, n. 20, Florianópolis, $2016 . \quad$ Disponível em: http://pepsic.bvsalud.org/scielo.php?script=sci_arttext\&pid=S1984-

21472016000300010\&lng=pt\&nrm=iso\&tlng=pt. Acesso em: 24 ago. 2020.

JODELET, D. Representações sociais: um domínio em expansão. In: JODELET, D. (Org.). As representacõos sociais. Trad. Lilian Ulup. Rio de Janeiro: EdUERJ. 2001. p. 17-44.

JODELET, D. A cidade e a memória. In: DEL RIO, V.; DUARTE, C. R.; RHEINGANTZ, P. A. (Org.). Projeto do lugar: colaboração entre Psicologia, Arquitetura e Urbanismo. Rio de Janeiro: Contra Capa Livraria, 2002. (Coleção ProArquitetura). p. 31-43.

JOVCHELOVITCH, S. Social Representations and narrative: stories of public life in Brazil. In: LÁSZLÓ, J.; ROGERS S. W. Narrative approaches in Social Psychology. Budapest: New Mandate. 2002. p. 47-58.

LLOYD, B.; DUVEEN, G. Social representations, social identities and scholing. In: LLOYD, B; DUVEEN, G. Gender identities and education: The impact of starting school. Londres: Harvester Wheatsheaf, 1992. Duveen (1992).

LORENSINI, S. R. G. Educação infantil na rede pública de Cuiabá: análise da construção de um projeto cultural para as crianças de até 3 anos, ambiguidades do percurso. 297 f. Tese (Doutorado) - Universidade Federal de Mato Grosso. Programa de Pós Graduação em Educação. Cuiabá, 2018. 
LÜDKE, M.; ANDRÉ, M. E. D. A. Pesquisa em educação: abordagens qualitativas. São Paulo: EPU, 1986.

MARKOVÁ, I. A Fabricação da Teoria de Representações Sociais. Trad. Beatriz Rodrigues e João Barros. Cadernos de Pesquisa, v. 47, n. 163, p. 358-375, jan./mar., 2017 a.

MARKOVÁ, I. Mente dialógica: senso comum e ética. Trad. Lilian Ulup. Cambridge University Press: São Paulo: Fundação Carlos Chagas. Curitiba: PUCPRESS, 2017b.

MAZZOTTI, T. Núcleo figurativo: themata ou metáfora?. Revista do Programa de Estudos Pósgraduados em Psicologia da Educação, Pontifícia Universidade Católica de São Paulo, n. 1, p. 105114, dez. 1995.

MOSCOVICI, S. Representações sociais: investigações em psicologia social. Editado em inglês por Gerard Duveen: traduzido do inglês por Pedrinho A. Guareschi. 7 ed. Petrópolis, RJ: Vozes, 2010.

OLIVEIRA-FORMOSINHO, J.; FORMOSINHO, J. Pedagogia-em-Participação: em busca de uma práxis holística. In: OLIVEIRA-FORMOSINHO, J. (Org.). Documentação pedagógica e avaliação na educação infantil: um caminho para a transformação. Porto Alegre: Penso, 2019. p. $27-54$.

PLÉH, C. Narrative constructions of texts and the self. In: LÁSZLÓ, J.; ROGERS, S. W. Narrative approaches in Social Psychology. Budapest: 2002. p. 90-109.

PURKHARDT, S. C. stories that change the world: the role of narrative in transforming Social representations. In: LÁSZLÓ, J.; ROGERS S. W. Narrative approaches in Social Psychology, Budapest, 2002. p. 59- 73.

SENNETT, R. The conscience of the eye: the design and social life of cities. New York: Norton \& Company, 1990.

VASCONCELLOS, T. Infância e patrimônio. Revista da FAEEBA - Educação $e$ Contemporaneidade, Salvador, v. 18, n. 31, p. 15-20, jan./jun. 2009. Disponível em: https://pdfslide.net/documents/educacao-infantil1.html. Acesso em: 16 set. 2019.

VIGOTSKI, L. S (Lev Semionovich). Imaginação e criação na infância: ensaio psicológico: livro para professores; apresentação e comentário Ana Luiza Smolka. Trad. Zoia Prestes. São Paulo: Ática, 2009.

RECEBIDO: 01/06/2020

APROVADO: $28 / 07 / 2020$

RECEIVED: 06/01/2020

APPROVED: 07/28/2020

RECIBIDO: 01/06/2020

APROBADO: 28/07/2020 